\title{
Performance comparisons of triple friction pendulum bearings with different sliding surface properties
}

\author{
Muhammad Zulfakar iD, Ali Ihsan Karakas*iD \\ Karadeniz Technical University, Department of Civil Engineering, Trabzon, Turkey
}

\begin{abstract}
In this study the time history analyses are carried out three dimensionally for a simple five-story concrete structure seismically isolated incorporating triple friction pendulum bearings with different sliding surface properties with the help of the ABAQUS finite element program. The altering friction surface properties are friction coefficient and radius of curvature. The performances of the various isolators are compared with each other as well as with those of a fixed based structure. For this purpose, maximum relative story displacements, story accelerations and column base shear forces are investigated as seismic reactions. According to the analysis results it can be stated that the seismic reactions of isolated structures are significantly reduced when compared to those of the fixed supported structure. Additionally, when triple friction pendulum bearing isolators with different friction coefficients and friction surface radii are compared, it can be observed that increasing the friction coefficient increases the reactions of the structure while increasing the friction surface radii decreases the reactions.
\end{abstract}

\section{Keywords}

Seismic isolator; Triple friction pendulum bearing; Friction coefficient; Friction surface radius; Time history analysis

Received: 1 July 2021; Accepted: 12 September 2021

ISSN: 2630-5763 (online) (C) 2021 Golden Light Publishing All rights reserved.

\section{Introduction}

Earthquake is one of the natural events that often occur on the earth surface. When an earthquake occurs, the earth's surface shakes horizontally and/or vertically. This is because of the movements of some tectonic plates in the earth's lithosphere. Such events may produce earthquake intensities ranging from too low intensities to be felt to high intensities that can damage everything on the surface of the earth. Most commonly buildings are damaged due to such earthquakes since they react dynamically to the ground motion. One of the solutions to this phenomenon is to seismically isolate buildings from the earthquake ground motions.

Fig. 1 shows the behavior of the isolated and fixed based structure during an earthquake. The isolated structure is shown to have no direct contact with the ground which makes it less prone to seismic effects. The isolation system physically separates the structure from ground motion, and it reduces the force on the structure generated by the earthquake. In other words, seismic isolation systems work by increasing the vibration period of the structure beyond the fundamental period of the earthquake ground motion, thereby reducing the amplification of the inertial loads due to resonance

* Corresponding author

Email: aliihsan.karakas@ktu.edu.tr 


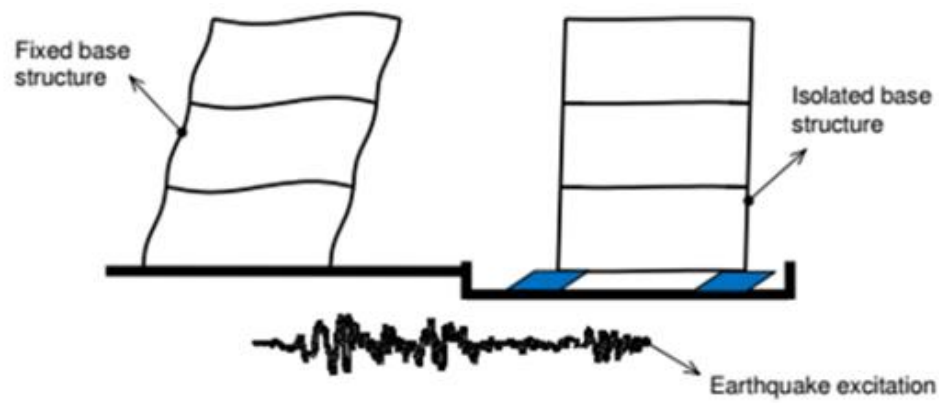

Fig. 1. Deformation profiles of a fixed based and isolated structure

effect. The increase in period reduces the seismic responses of the structure including displacements, accelerations and story shears to acceptable and safe values. Thus, the reduction of responses keeps the structure in the elastic or nearly elastic range [1].

There are basically two types of seismic isolation systems that are frequently used. These are the rubber isolator and friction pendulum isolator systems shown in Figs. 2(a) and (b), respectively. A rubber isolator is highly rigid in the vertical direction while it incorporates varying layers of steel and rubber to provide flexibility in the horizontal direction. Pendulum isolators with curved surfaces consist of concave upper and lower plates and intermediate slider with spherical surfaces. Friction pendulum isolators may have different number of friction surfaces. Depending on the friction surface number they are called as single, double or triple friction pendulum isolators.

Many studies have been conducted in the literature to examine the potential of friction pendulum isolators to reduce the effects of earthquakes on structures. For example, Fenz and Constantinou [2-5] investigated the behaviors of double and triple pendulum isolators and also conducted theoretical and experimental researches on the spherical friction pendulum isolators with adaptive behaviors. Pigouni et al. [6] conducted experimental dynamic tests on full scale pendulum isolators with curved surface sliders. Deringöl [7] evaluated the seismic performances of some twodimensional steel frames with different heights and isolated with friction pendulum isolators under various seismic excitations. Moreover, Castaldo and Tubaldi [8] investigated the effects of ground motion characteristics on the optimum response of single friction pendulum isolators. Calvi et al. [9] discusses the possibility of using materials with different friction properties in order to increase the energy absorption capacity of flat and curved surface pendulum isolators. Yurdakul and Ateş [10] studied the efficiency of triple friction pendulum isolators against single and double friction seismic isolation devices performing structural analyses. However, the isolated structures considered in the previously mentioned studies have been modeled as single or multi-degree freedom systems with simple spring models of friction pendulum isolators. Therefore, the purpose of this study is to model a building structure isolated with triple friction pendulum isolators three dimensionally using ABAQUS finite element program [11] to investigate the influences of sliding surface friction coefficients and radii on the seismic responses. The responses are obtained from the geometrically nonlinear time history analyses. So, the behaviors of the building and the isolators are investigated more realistically than the spring models studied in the literature.

\section{Triple friction pendulum bearing isolator}

Triple friction pendulum bearing (TFPB) isolator is a commonly investigated type of isolators. The advantages of a TFPB isolator have been described in many studies [12-15]. The components and geometrical notations of a typical TFPB isolator are shown in Fig. 3. 


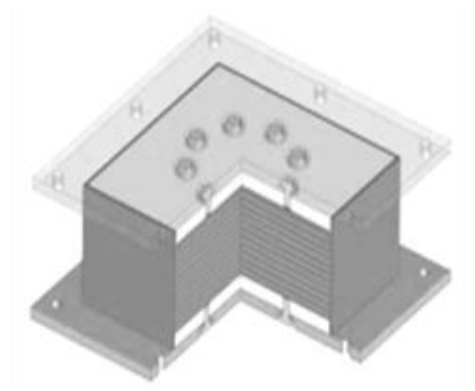

(a)

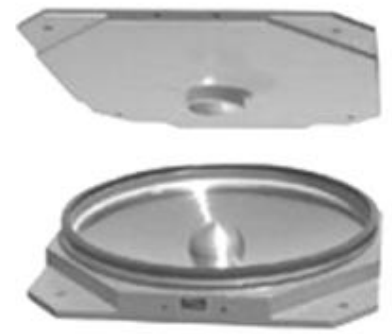

(b)

Fig. 2. a) Rubber and b) friction pendulum isolators
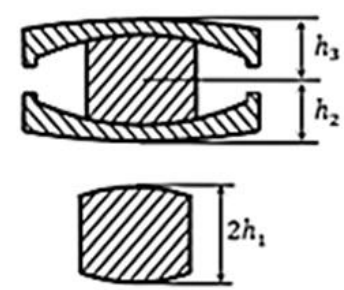

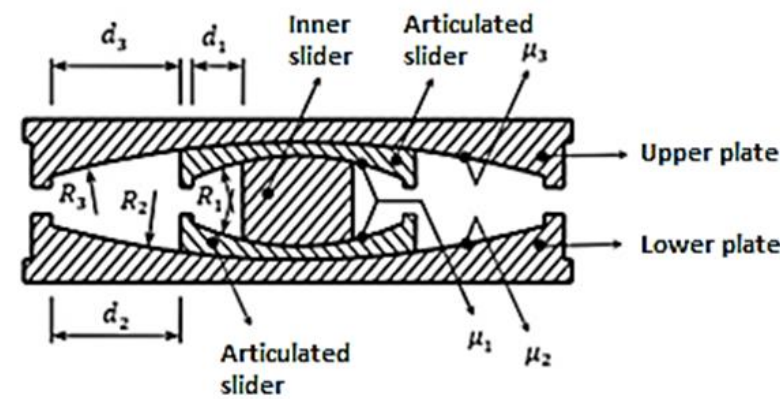

slider

Fig. 3. Components and geometrical notations of a TFPB isolator

The TFPB consists of an inner slider that can slide between two articulated concave sliders with spherical surfaces and articulated sliders that can slide between the upper and lower concave plates. The friction between surfaces resists small horizontal loads without movement and dissipates energy during sliding between surfaces under large horizontal loads. The curvature of surfaces along with the vertical load creates a restoring force (centering force) when horizontal displacement occurs [16].

Theoretical behavior of a TFPB isolator is described in detail by Fenz and Constantinou [3] and Morgan and Mahin [17]. Fig. 4 shows the normalized hysteretic loop or force-displacement loop of a typical triple friction pendulum bearing isolator. This loop is used for the finite element model verification of the isolator.

The normalized horizontal force is obtained as $f$ $=F / W$. Here, $F$ is the applied horizontal force and $W$ is the vertical force applied on the isolator. The normalized sttiffnesses of the force-displacement loop shown in Fig. 4 are:

$$
\begin{aligned}
& k_{1}=\frac{1}{2 R_{\text {eff } 1}}, k_{2}=\frac{1}{R_{\text {eff } 1}+R_{\text {eff } 2}}, k_{3}=\frac{1}{R_{e f f 2}+R_{e f f 3}}, \\
& k_{4}=\frac{1}{R_{\text {eff } 1}+R_{\text {eff } 3}}, k_{5}=\frac{1}{2 R_{\text {eff } 1}}
\end{aligned}
$$

and normalized horizontal forces are:

$$
\begin{aligned}
& f_{2}^{*}=\mu_{2}, f_{3}^{*}=\mu_{3}, f_{4}^{*}=\mu_{2}+\frac{d_{2}}{R_{\text {eff } 2}}, \\
& f_{5}^{*}=\mu_{3}+\frac{d_{3}}{R_{\text {eff } 3}}, f_{6}^{*}=f_{5}^{*}+k_{5}\left(u_{6}^{*}-u_{5}^{*}\right)
\end{aligned}
$$

and the lateral displacements corresponding to the normalized horizontal forces can be computed as given below:

$$
\begin{aligned}
& u_{2}^{*}=2 R_{\text {eff } 1}\left(\mu_{2}-\mu_{1}\right) \\
& u_{3}^{*}=R_{e f f 1}\left(\mu_{2}+\mu_{3}-2 \mu_{1}\right)+R_{\text {eff } 2}\left(\mu_{3}-\mu_{2}\right) \\
& u_{4}^{*}=u_{3}^{*}+\left(\frac{d_{2}}{R_{\text {eff } 2}}+\mu_{2}-\mu_{3}\right)\left(R_{\text {eff } 2}+R_{\text {eff } 3}\right)
\end{aligned}
$$




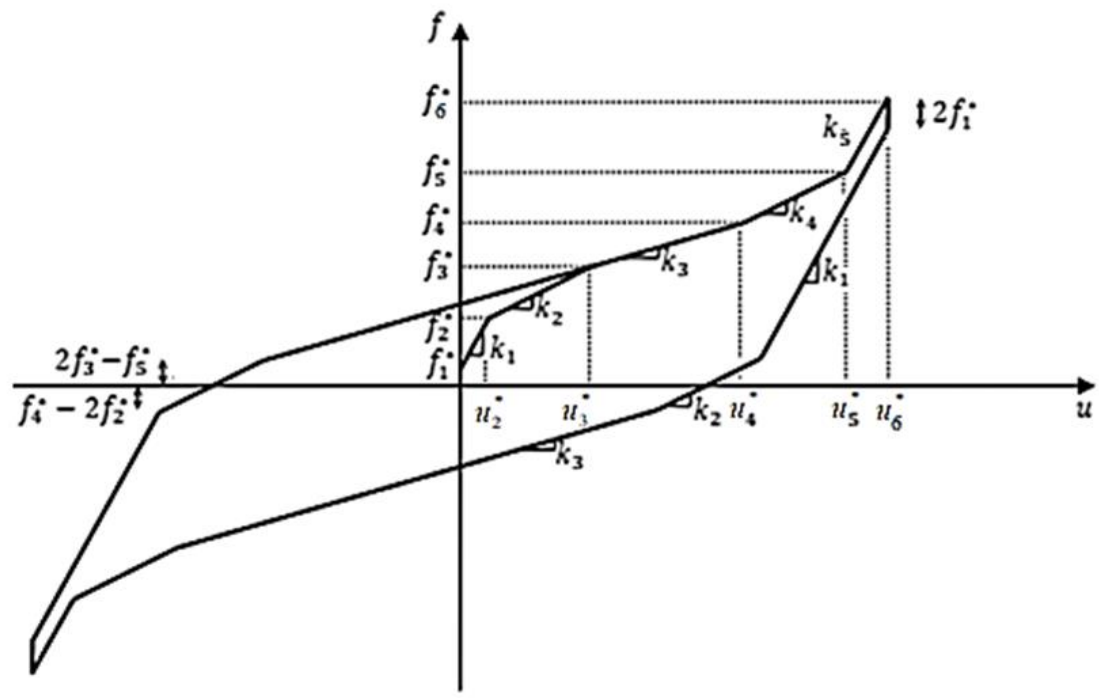

Fig. 4. Force-displacement loop of a TFPB isolator

$$
\begin{aligned}
& u_{5}^{*}=u_{4}^{*}+\left(\frac{d_{3}}{R_{e f f 3}}+\mu_{3}-\frac{d_{2}}{R_{e f f} 2}-\mu_{2}\right)\left(R_{e f f 1}+R_{e f f 3}\right) \\
& u_{6}^{*}=d_{1}+d_{2}+d_{3}+\frac{R_{e f f 1} 1}{R_{e f f 3}} d_{3}-\frac{R_{e f f 1}}{R_{e f f} 2} d_{2}
\end{aligned}
$$

where the effective radii used in the above equations are calculated as given below:

$$
\begin{aligned}
& R_{\text {eff } 1}=\left(R_{1}-h_{1}\right), \\
& R_{\text {eff } 2}=\left(R_{2}-h_{2}\right), \\
& R_{\text {eff } 3}=\left(R_{3}-h_{3}\right)
\end{aligned}
$$

\section{Structure and isolator models}

In this study a simple 5-storey building with TFPB isolators is modelled three dimensionally using the ABAQUS finite element program as shown in Figure 5. The columns and beams of the structure have a cross sectional size of $30 \times 30 \mathrm{~cm}$. The spacing between the columns and the story height is $3.5 \mathrm{~m}$. The modulus of elasticity, Poisson ratio and specific gravity of concrete material are taken into account as $20 \mathrm{GPa}, 0.18$ and $24 \mathrm{kN} / \mathrm{m}^{3}$, respectively [18]. Column 1 and 2 shown in Fig. 5 are selected to study the effects of earthquake on different columns in the axis of $\mathrm{X}$.

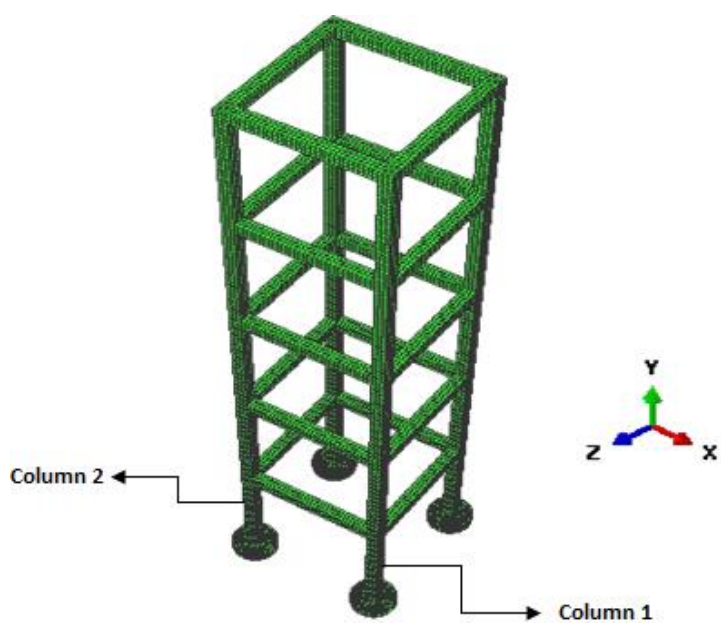

Fig. 5. Finite element model of the isolated structural system

Hexahedral, continuous, three-dimensional, 8noded and 1-node reduced integration C3D8R type finite elements are used in the finite element modelling of the structure [11]. The finite element model of the TFPB isolator is shown in Fig. 6. The same C3D8R finite element is used for the isolator. The ultimate tensile strength and yield stress of the S355 steel material of the isolator are $490 \mathrm{MPa}$ and $355 \mathrm{MPa}$. And the modulus of elasticity and Poisson ratio of the steel material taken into account in the model are $210 \mathrm{GPa}$ and 0.3 according to EN1993-1-1, respectively [19]. 


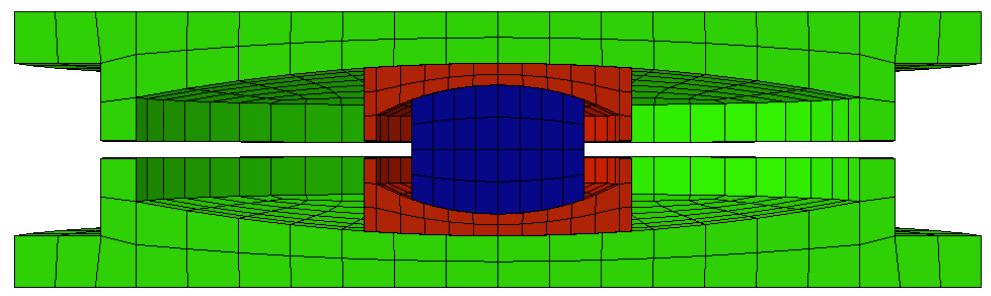

Fig. 6. Finite element model of a TFPB isolator

The geometrical and material properties of the TFPB isolators considered in this study are given in Table 1. The friction surface curvature radii and friction coefficients are altered as given in Table 1 and the remaining properties are kept constant as $h_{1}$ $=75 \mathrm{~mm}, h_{2}=h_{3}=100 \mathrm{~mm}$ and $d_{1}=40 \mathrm{~mm}, d_{2}=d_{3}$ $=265 \mathrm{~mm}$.

\section{Earthquake record for time history analyses}

The time-acceleration record of the Northridge-011994 earthquake is used for the time history analyses to be conducted in this study. The acceleration and displacement histories of the earthquake with respect to time are shown in Figs. 7 and 8 , respectively. The peak ground acceleration (PGA) value of the earthquake is $0.583 \mathrm{~g}$. Additionally, it can be seen from Fig. 8 that the maximum ground displacement of the Northridge earthquake is smaller than the maximum displacement capacity of the TFPB isolator.

\section{Finite element model verification}

The force-displacement cycles obtained by the analytical formulas given previously have been compared with finite element results for the verification of the TFPB isolator finite element model. The total vertical load on the TFPB2 isolator considered is $2000 \mathrm{kN}$. This vertical load is applied to the surface area of the upper plate of the isolator models as a uniformly distributed pressure.

Fig. 9 shows the comparison of the forcedisplacement cycles obtained using Eqs. (1-8) and that obtained using finite element model of the isolator. As shown from Fig. 9 the results obtained are close to each other for both models. For this reason, it can be stated that the existing TFPB isolator finite element model can be used to study the dynamic responses.

\section{Effects of sliding surface friction coefficients on seismic reactions}

In this section, maximum relative story displacements, story accelerations and column base shear forces of the structure isolated using TFPB isolators with different surface friction coefficients are examined comparatively with the results of the fixed based structure.

Fig. 10 shows the changes in the maximum relative story displacements of the structure for different support types of TFPB1, TFPB2, TFPB3 isolators and fixed base. Maximum relative story displacement is the maximum displacement value obtained at the story level relative to the base of the structure during the earthquake.

The maximum relative displacement at the 5 th story is obtained as $95.03 \mathrm{~mm}$ during the Northridge earthquake while for structures with isolators TFPB1, TFPB2 and TFPB3 these values are 37.72 $\mathrm{mm}, 49.18 \mathrm{~mm}$ and $54.34 \mathrm{~mm}$, respectively. Accordingly, the reduction ratios in relative displacement with respect to fixed based results are $60.3 \%, 48.2 \%$ and $42.8 \%$, respectively. Therefore, it can be stated that all of the friction pendulum isolators significantly reduce the maximum relative displacement compared to fixed based structure. Moreover, it can be concluded that an increase in the surface friction coefficient increases the relative displacement of the structure.

Additionally, Fig. 11 depicts the history of the relative displacement at the $5^{\text {th }}$ story during the Northridge earthquake. 
Table 1. Geometrical and material properties of various TFPB isolators

\begin{tabular}{ccccccc}
\hline Model & $R_{1}$ & $R_{2}$ & $R_{3}$ & $\mu_{1}$ & $\mu_{2}$ & $\mu_{3}$ \\
\hline TFPB1 & 300 & 2240 & 2240 & $\mathbf{0 . 0 1}$ & $\mathbf{0 . 0 2}$ & $\mathbf{0 . 0 4}$ \\
TFPB2 & 300 & 2240 & 2240 & $\mathbf{0 . 0 1}$ & $\mathbf{0 . 0 3}$ & $\mathbf{0 . 0 6}$ \\
TFPB3 & 300 & 2240 & 2240 & $\mathbf{0 . 0 1}$ & $\mathbf{0 . 0 4}$ & $\mathbf{0 . 0 8}$ \\
TFPB4 & $\mathbf{3 0 0}$ & $\mathbf{2 0 0 0}$ & $\mathbf{2 0 0 0}$ & 0.01 & 0.03 & 0.06 \\
TFPB5 & $\mathbf{3 0 0}$ & $\mathbf{2 2 4 0}$ & $\mathbf{2 2 4 0}$ & 0.01 & 0.03 & 0.06 \\
TFPB6 & $\mathbf{3 0 0}$ & $\mathbf{2 4 8 0}$ & $\mathbf{2 4 8 0}$ & 0.01 & 0.03 & 0.06 \\
\hline
\end{tabular}

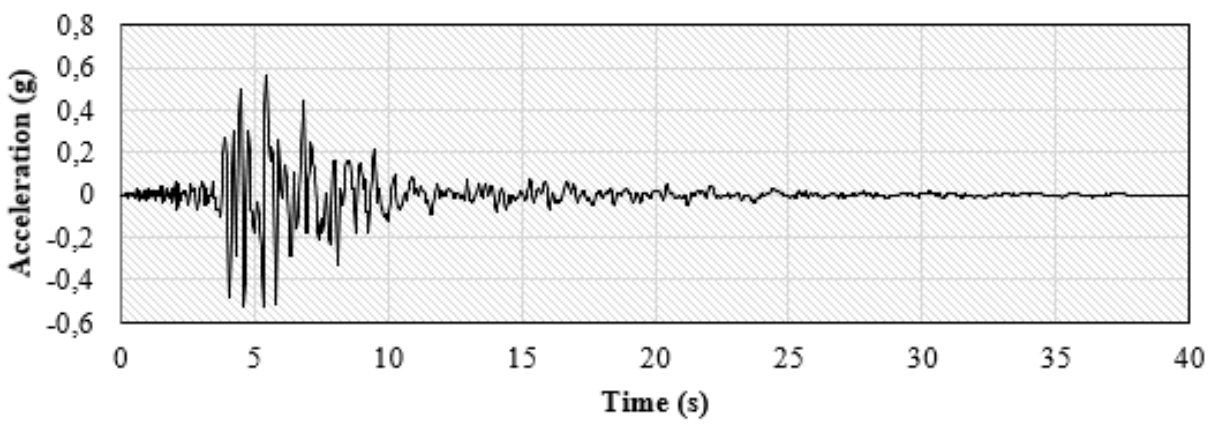

Fig. 7. Northridge 1994 earthquake acceleration-time record

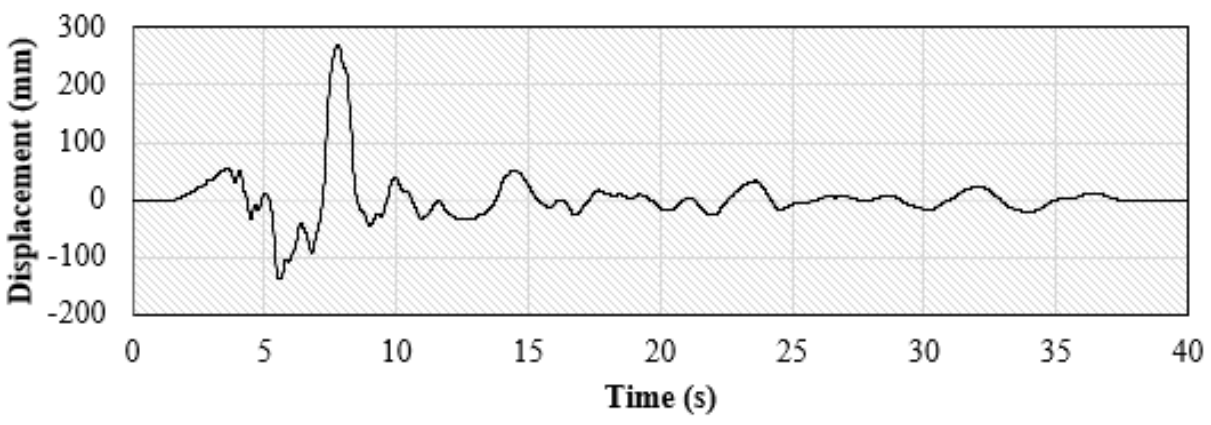

Fig. 8. Northridge 1994 earthquake displacement-time record

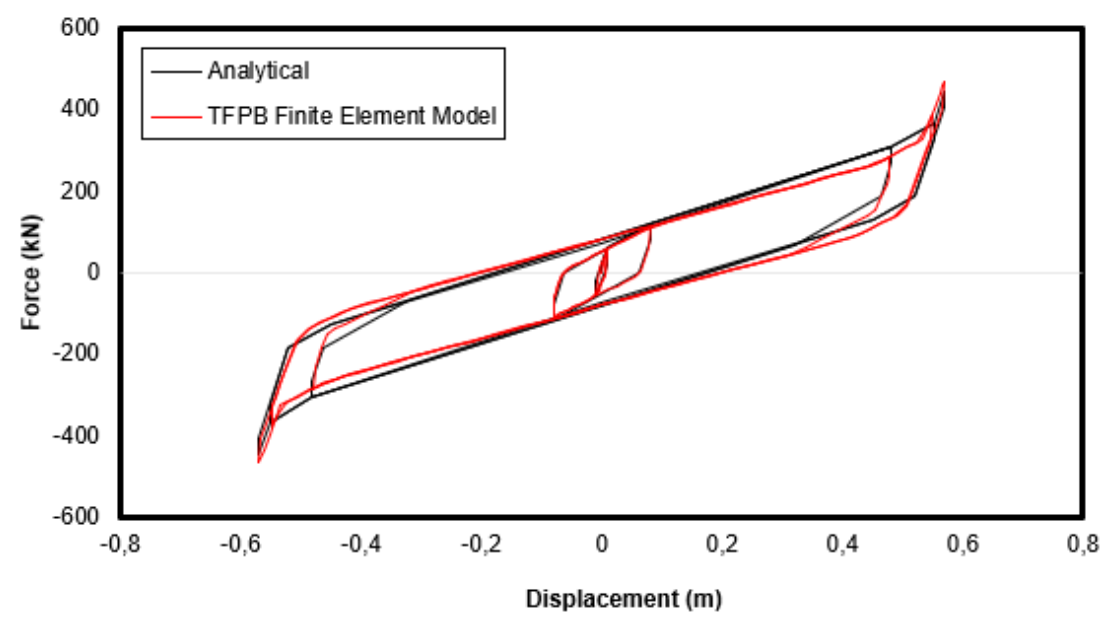

Fig. 9. The force-displacement cycles of the TFPB isolator 


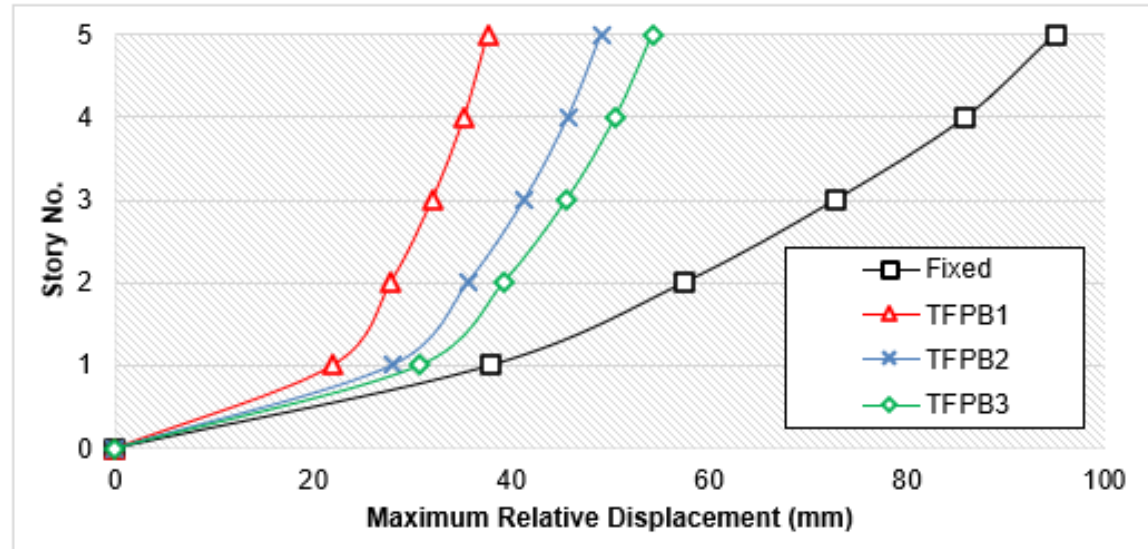

Fig. 10. Maximum relative displacements of the fixed based and isolated structures

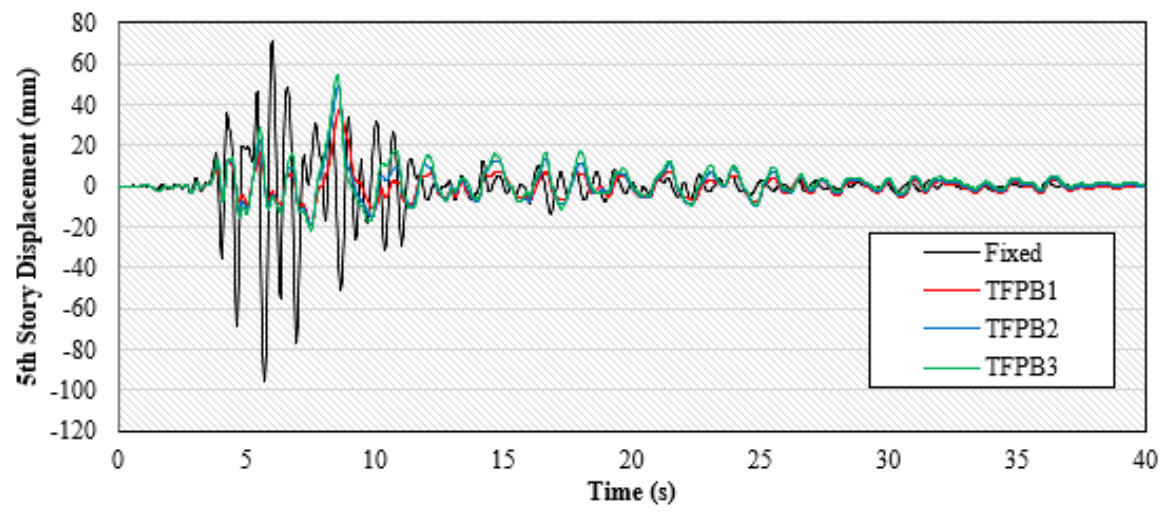

Fig. 11. Relative story displacements of the fixed based and isolated structures during the earthquake

Fig. 12 shows the maximum story accelerations due to the Northridge earthquake for the fixed based and isolated structures. For the fixed based structure, the accelerations of the first two stories are lower than the ground acceleration while the upper stories have larger or magnified accelerations. However, the reduced ground acceleration is transferred to the isolated structures and the acceleration values decrease as the floor height increases and become nearly uniform over the height. Maximum acceleration at the $5^{\text {th }}$ story for the fixed based structure is $0.853 \mathrm{~g}$ while it is $0.104 \mathrm{~g}, 0.131 \mathrm{~g}$ and $0.141 \mathrm{~g}$ for TFPB1, TFPB2 and TFPB3 isolated structures, respectively. Accordingly, the reduction rates of the maximum accelerations at the $5^{\text {th }}$ story are $87.9 \%, 84.6 \%$ and $83.5 \%$, respectively. Therefore, it can be stated that the friction pendulum isolator with minimum friction coefficient reduces the maximum acceleration to the greatest extent compared to the fixed based structure.

Moreover, Fig. 13 shows the history of the acceleration at the $5^{\text {th }}$ story during the Northridge earthquake. It can be seen that the accelerations of the isolated structures do not change largely during the earthquake when compared to the fixed based structure.

Fig. 14 shows the maximum base shear forces of columns 1 and 2 of the fixed based and isolated structures. Maximum base shear forces of fixed based columns 1 and 2 are $42.85 \mathrm{kN}$ and $41.01 \mathrm{kN}$, respectively. Those of structures isolated with TFPB1, TFPB2 and TFPB3 are $7.36 \mathrm{kN}, 10.02 \mathrm{kN}$ and $12.06 \mathrm{kN}$ for column 1 and $5.26 \mathrm{kN}, 6.97 \mathrm{kN}$ and $8.96 \mathrm{kN}$ for column 2 , respectively. 


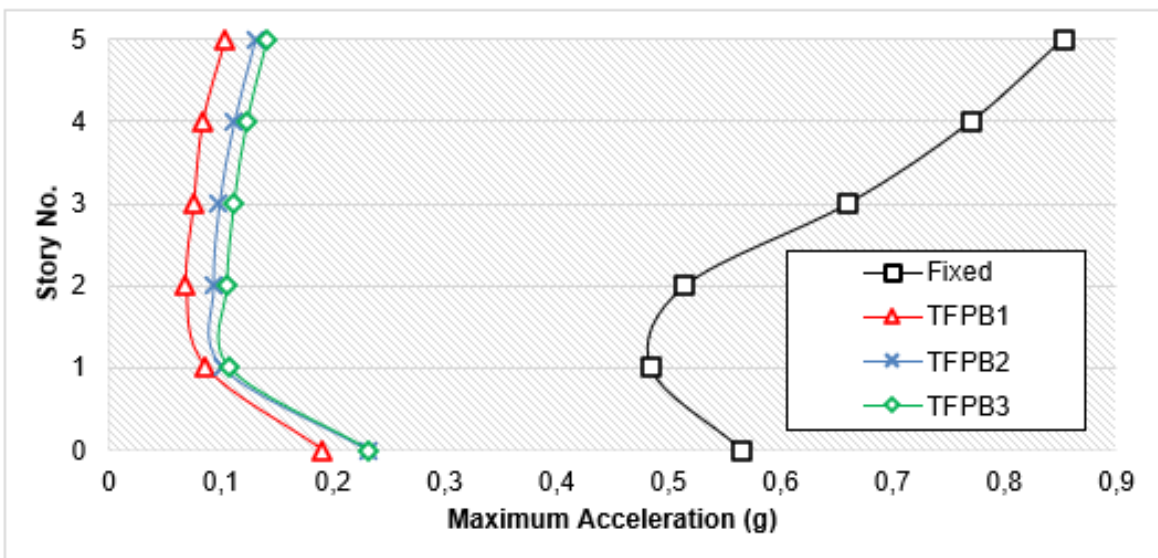

Fig. 12. Maximum story accelerations of the fixed based and isolated structures

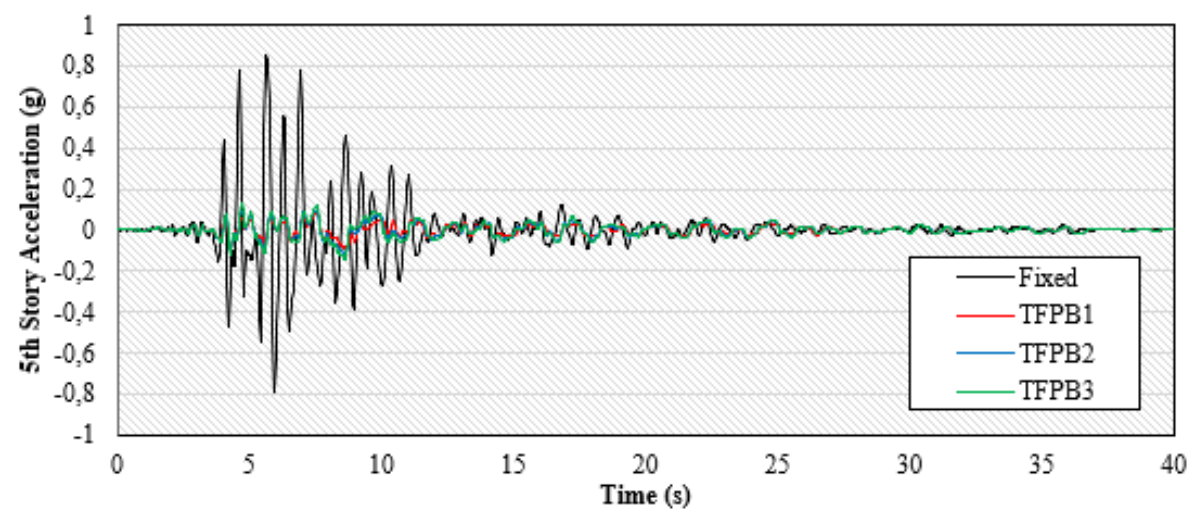

Fig. 13. Accelerations of the fixed based and isolated structures during the earthquake

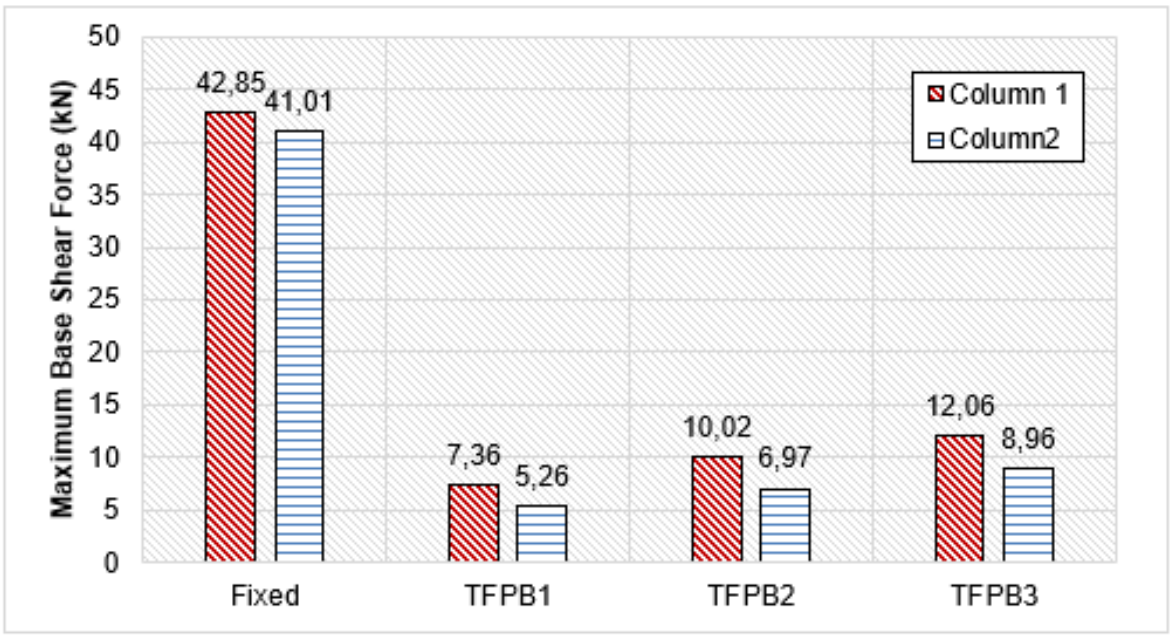

Fig. 14. Maximum column base shear forces of the fixed based and isolated structures 
According to these values, it can be concluded that the base shear forces of the isolated structures are quite low compared to fixed based structure and the larger coefficient of friction increases the base shear forces formed in the columns.

Figs. 15 and 16 depict the force-displacement cycles formed during the earthquake in TFPB 1 and TFPB3 isolators under Column 1, respectively. The maximum horizontal displacements and corresponding maximum shear forces generated on the isolators can be obtained using these cycles. Also, it can be stated that the energy dissipated by the TFPB3 isolator is larger than that of TFPB1 isolator when the total area of the cycles is considered.

\section{Effects of friction surface radii on seismic reactions}

In this section, maximum relative story displacements, story accelerations and column base shear forces of the structures isolated using TFPB isolators with different friction surface radii are investigated comparatively with the results of the fixed based structure.

Fig. 17 shows the changes in the maximum relative story displacements of the structure for different support types of TFPB4, TFPB5, TFPB6 isolators and fixed base. The maximum relative displacement at the $5^{\text {th }}$ story is obtained as 95.03 $\mathrm{mm}$ during the Northridge earthquake while for structures with isolators TFPB4, TFPB5 and TFPB6 these values are $54.81 \mathrm{~mm}, 49.18 \mathrm{~mm}$ and $45.34 \mathrm{~mm}$, respectively. Accordingly, the reduction ratios in relative displacement with respect to fixed based results are $42.3 \%, 48.2 \%$ and $52.3 \%$, respectively. Thus, it can be stated that the larger friction surface radius the smaller relative story displacements.

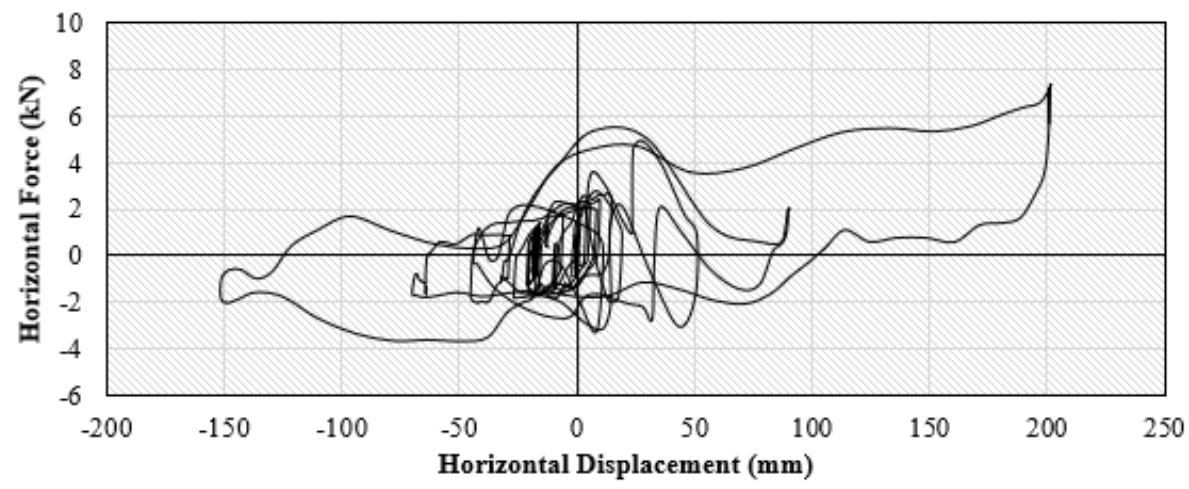

Fig. 15. Force-displacement cycles of TFPB 1 isolator under Column 1

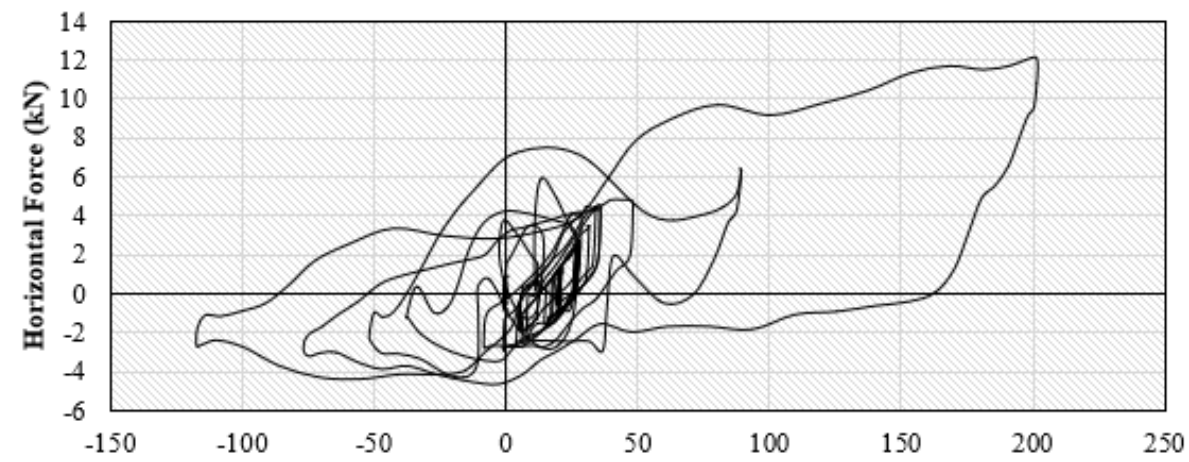

Fig. 16. Force-displacement cycles of TFPB 3 isolator under Column 1 


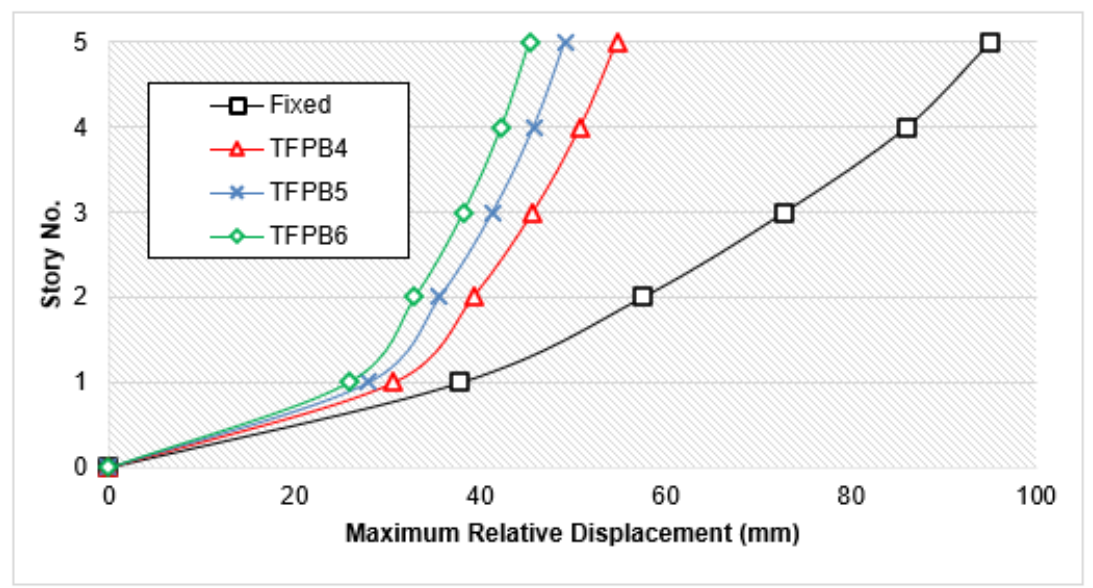

Fig. 17. Maximum relative displacements of the fixed based and isolated structures

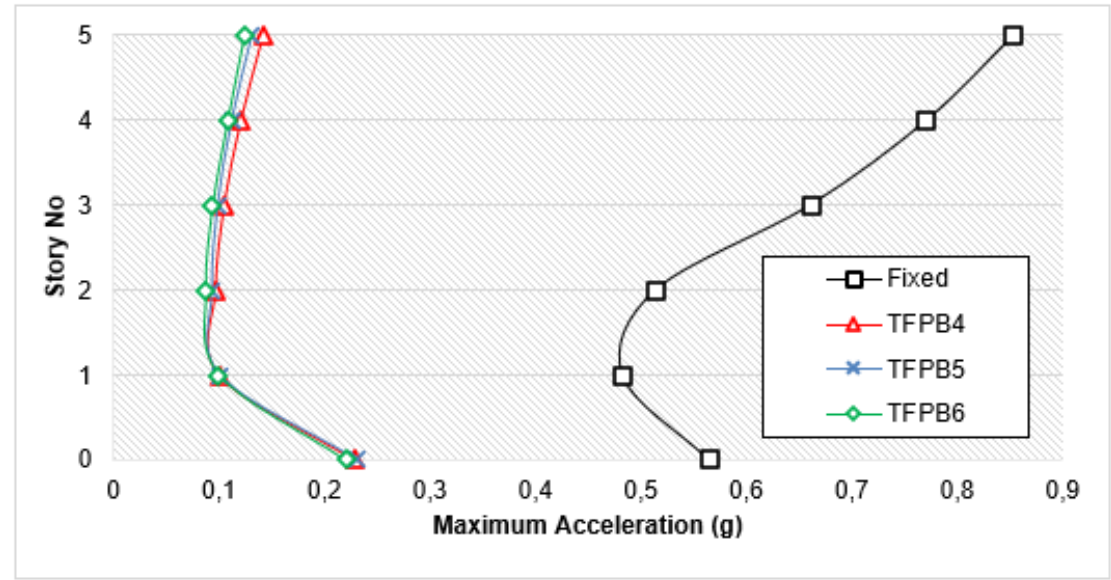

Fig. 18. Maximum story accelerations of the fixed based and isolated structures

Fig. 18 shows the maximum story accelerations of structures with isolators having different friction surface radii. The decreasing ratios in the maximum accelerations at the $5^{\text {th }}$ story for TFPB4, TFPB5, TFPB6 isolators are $83.3 \%, 84.6 \%$ and $85.4 \%$, respectively, when compared to fixed based results. Accordingly, even the ratios are close to each other, it can be expressed that the friction pendulum isolator with larger friction surface radii reduces the maximum acceleration larger.

Finally, Fig. 19 demonstrates the maximum base shear forces of columns 1 and 2 of the structures isolated with TFPB4, TFPB5 and TFPB6. The shear values are $11.02 \mathrm{kN}, 10.02 \mathrm{kN}$ and $9.26 \mathrm{kN}$ for column 1 and $7.18 \mathrm{kN}, 6.97 \mathrm{kN}$ and $6.79 \mathrm{kN}$ for column 2, respectively. According to these values, it can be concluded that the base shear forces of the isolated structures are reduced slightly with increasing friction surface radii.

\section{Conclusions}

In this study, the time history analyses of a simple five-story concrete structure which is seismically isolated with triple friction pendulum bearing (TFPB) isolators are carried out three dimensionally using the ABAQUS finite element program. 


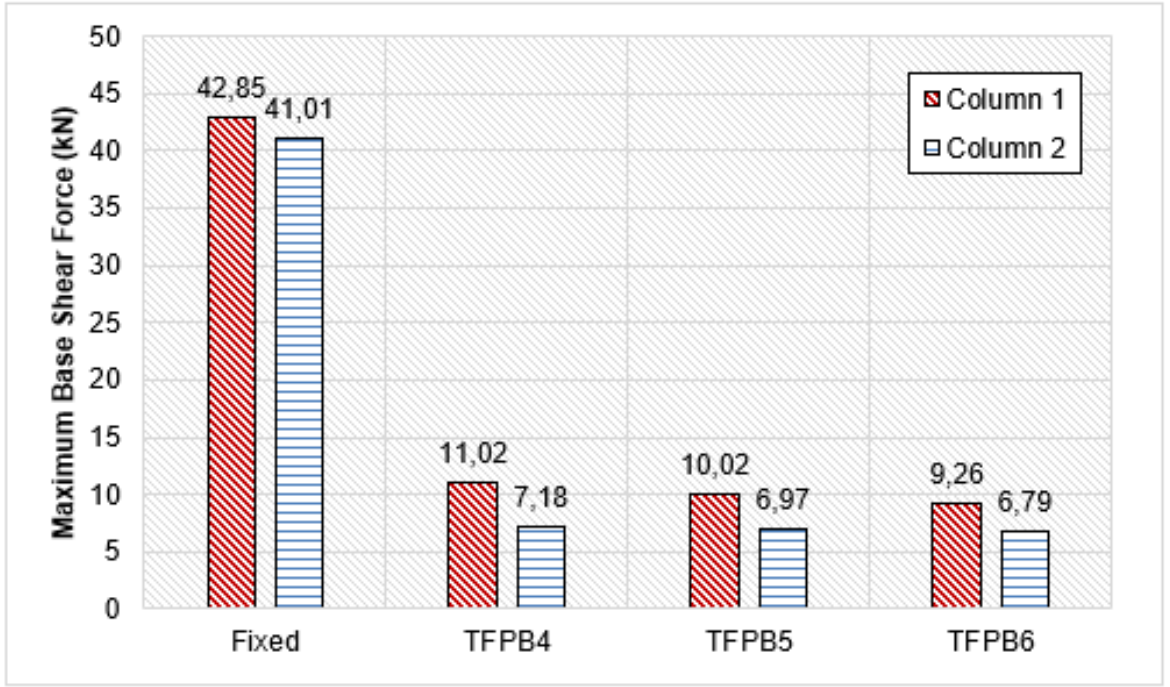

Fig. 19. Maximum column base shear forces of the fixed based and isolated structures

Seismic responses of the structure such as maximum relative story displacements, story accelerations and column base shear forces are investigated by changing the friction coefficients and friction surface radii of the isolators. These responses are also compared with the results of fixed-based structure. The main results of the study can be summarized as follows:

- When each of the seismically isolated structures is compared with the fixed based structure it can be observed that the relative story displacements, story accelerations and base shear forces of the structure are significantly decreased.

- When the structures isolated with TFPB1, TFPB2 and TFPB3 isolators having different friction coefficients are examined it can be seen that an increase in friction coefficients increases the relative displacements, maximum accelerations and column base shear forces in the structure.

- As far as the structures isolated with TFPB4, TFPB5 and TFPB6 isolators having different friction surface curvature radii are considered, it can be stated that increasing the radius of curvature decreases the relative displacements, maximum accelerations and column base shear forces in the structure.

\section{Declaration of conflicting interests}

The author(s) declared no potential conflicts of interest with respect to the research, authorship, and/or publication of this article.

\section{Acknowledgments}

The first author has been supported by Türkiye Scholarships with a scholarship which is gratefully acknowledged.

\section{References}

[1] Namiranian P, Ghodrati Amiri G, Veismoradi S (2016) Near-fault seismic performance of triple variable friction pendulum bearing. Journal of Vibroengineering 18:2293-2303.

[2] Fenz DM, Constantinou MC (2006) Behaviour of the double concave Friction Pendulum bearing. Earthquake Engineering and Structural Dynamics 35:1403-1424.

[3] Fenz DM, Constantinou MC (2008) Modeling triple friction pendulum bearings for responsehistory analysis. Earthquake Spectra 24:10111028.

[4] Fenz DM, Constantinou MC (2008) Spherical sliding isolation bearings with adaptive behavior: Experimental verification. Earthquake Engineering and Structural Dynamics 37:185-205.

[5] Fenz DM, Constantinou MC (2008) Spherical sliding isolation bearings with adaptive behavior: 
Theory. Earthquake Engineering and Structural Dynamics 37:163-183.

[6] Pigouni AE, Castellano MG, Infanti S, Colato GP (2019) Full-scale dynamic testing of pendulum isolators (Curved surface sliders). Soil Dynamics and Earthquake Engineering 130(Mar):105983.

[7] Deringöl AH (2018) Seismic performance of steel moment frames with variable friction pendulum systems under real ground motions. International Advanced Researches and Engineering Journal 2:208-216.

[8] Castaldo P, Tubaldi E (2018) Influence of ground motion characteristics on the optimal single concave sliding bearing properties for base-isolated structures. Soil Dynamics and Earthquake Engineering 104:346-364.

[9] Calvi PM, Moratti M, Calvi GM (2016) Seismic isolation devices based on sliding between surfaces with variable friction coefficient. Earthquake Spectra 32:2291-2315.

[10] Yurdakul M, Ateş Ş (2011) Modeling of triple concave friction pendulum bearings for seismic isolation of buildings. Structural Engineering and Mechanics 40:315-334.

[11] ABAQUS, Analysis User's Guide Volume IV: Elements Version 6.14, Dassault Systemes Simulia, Inc., Providence, RI, USA, 2014.

[12] Xu Y, Guo T, Yan P (2019) Design optimization of triple friction pendulums for base-isolated high-rise buildings. Advances in Structural Engineering 22:2727-2740.
[13] Loghman V, Khoshnoudian F, Banazadeh M (2015) Effect of vertical component of earthquake on seismic responses of triple concave friction pendulum base-isolated structures. Journal of Vibration and Control 21:2099-2113.

[14] Malekzadeh M, Taghikhany T (2012) Multi-stage performance of seismically isolated bridge using triple pendulum bearings. Advances in Structural Engineering 15:1181-1196.

[15] Reyes JC, Herrera MT, Paul Smith-Pardo J, Córdoba, LS (2020) Effective live load mass for storage buildings on friction-pendulum isolators. Engineering Structures 218(May):110843.

[16] Dao D (2012) Seismic response of a full-scale 5story steel frame building isolated by triple pendulum bearings under $3 \mathrm{D}$ excitations. $\mathrm{PhD}$ Dissertation, University of Nevada, Reno.

[17] Morgan TA, Mahin SA (2011) The use of base isolation systems to achieve complex seismic performance objectives. Tokyo Institute of Technology. In PEER Report 2011/06 (Issue July).

[18] Gere JM (2004) Mechanics of Materials, $6^{\text {th }}$ Edition. Thomson Learning, Inc., USA.

[19] EN 1993-1-1 (2005) Eurocode 3: Design of steel structures-Part 1-1: General rules and rules for buildings. 